\title{
RELAÇÃO PÚBLICO-PRIVADO NOS USOS DAS ORLAS DOS MUNICÍPIOS DE SERRA E VITÓRIA - ES
}

Recebido em: 06/02/2017

Aceito em: 21/08/2017

Leonardo Perovano Camargo

Lorenna Pereira Oliosi

Junia Helena dos Santos

Universidade Federal do Espírito Santo

Vitória - ES - Brasil

Carlos Nazareno Ferreira Borges

Universidade Federal do Pará

Belém - PA - Brasil

Kamila da Penha Braz DeFante

Universidade Federal do Espírito Santo

Vitória - ES - Brasil

RESUMO: Este estudo é uma discussão a partir do subprojeto de uma pesquisa que tem a intenção de investigar a relação público-privado a partir dos usos que a iniciativa privada estabelece sobre os espaços públicos. Analisaram-se os usos das orlas em projetos de intervenção com esporte e lazer e de como opera a política, de tal forma a identificar como estas ações incidem sobre os direitos constitucionalmente previstos de acesso ao esporte e ao lazer. Nos procedimentos metodológicos, utilizamos como planos de pesquisa os estudos descritivo e explicativo; mapeamentos e questionários com os responsáveis pelas intervenções. Os resultados apontam para concepções sobre espaço público como espaço para todos, mas, ocupado de acordo com interesses pessoais; concepção unívoca de benefícios nas parceiras e; oferta de serviços sem institucionalização e regulamentação, mostrando ausência de responsabilidades do Estado.

PALAVRAS CHAVE: Atividades de Lazer. Parcerias Público-Privadas. Setor Privado.

\section{PUBLIC-PRIVATE RELATIONSHIP IN THE USES OF THE BORDERS OF THE MUNICIPALITIES OF SERRA AND VITÓRIA - ES}

ABSTRACT: This study is a discussion from the subproject of a research that intends to investigate the public-private relationship of the uses of the private sector on public spaces. It was analyzed the uses of waterfront beaches in intervention projects with sports and leisure and how politics operates in such a way to identify how these actions affect the rights constitutionally previewed to this access to sport and leisure. In the methodological procedures, it was used as research plans the descriptive and 
explanatory studies; mapping and questionnaires with those responsible for interventions. The results indicate conceptions of public space as a space for everyone, but, used according to personal interests; univocal conception of the partner benefits and; offer without institutionalization and regulation services, showing the absence of responsibilities of the State.

KEYWORDS: Leisure Activities. Public-Private Sector Partnerships. Private Sector.

\section{Introdução}

A Constituição Federal Brasileira de 1988 colocou o esporte e lazer como direitos de todos os cidadãos, ampliando assim, as discussões acadêmicas e ações no campo da gestão pública. Os artigos $6^{\circ}$ e $217^{\circ}$ instituem que políticas de Estado deveriam ser aplicadas para a população, mobilizando a construção de políticas públicas nesta direção.

Nota-se que onde há demanda por serviços que deveriam ser oferecidos pelo Estado, mas não há capacidade no cumprimento desta demanda, a iniciativa privada acaba ocupando esta lacuna, vide o caso dos planos de saúde e educação particular.

Já no campo de esporte e lazer, a exploração privada dos espaços públicos vem ocorrendo em diversas localidades, principalmente nas partes privilegiadas das cidades, como as orlas urbanizadas.

Faz-se necessária a discussão desses usos, passando por diversas questões sociológicas e antropológicas para uma análise de maior qualidade, utilizando temas dessas áreas como desigualdade, classes, políticas públicas, educação, profissionalismo, além de discussões nos campos da saúde, sobretudo a educação física.

Nas análises de políticas públicas relacionadas a lazer encontramos um indicador importante que é a concepção que os gestores têm de lazer (MARCELINNO, 2001), e através desta análise justifica-se o crescimento de políticas de governo nesse setor nos 
últimos anos sustentadas no direito social garantido constitucionalmente (BORGES et al., 2009; AREIAS; BORGES, 2011).

Neste estudo, buscamos observar e descrever as relações entre os setores públicos e privados nos usos dos espaços públicos nas orlas dos municípios de Serra e Vitória no Espírito Santo.

Sendo assim o objetivo geral deste estudo é identificar as práticas de esporte e lazer privadas, nas orlas de Serra e Vitória-ES, observar como essas práticas se desenvolve, identificar a relação do poder público com a exploração privada destes espaços e analisar se e como incidem sobre os direitos sociais estabelecidos constitucionalmente no acesso ao esporte e ao lazer.

Temos também como objetivos específicos identificar em territórios delimitados, as políticas públicas de utilização dos espaços e equipamentos públicos e/ou espaços e equipamentos privados de esporte e lazer conveniados com o Estado; Analisar em territórios delimitados, como ocorre a parceria entre a iniciativa privada e o Poder Público na utilização dos espaços e equipamentos públicos e/ou espaços e equipamentos privados de esporte e lazer conveniados com o Estado; Compreender se e como as políticas de utilização dos espaços e equipamentos públicos e/ou espaços e equipamentos privados de esporte e lazer conveniados com o Estado, incidem sobre os direitos sociais estabelecidos constitucionalmente no acesso ao esporte e ao lazer.

Apresentamos a seguir, parte da revisão de literatura que consideramos fundamental para a fundamentação teórica e posterior discussão dos dados encontrados nesta pesquisa. 


\section{A Relação Público-Privado}

A ação do governo está intimamente ligada ao ideal de democracia que se tem. A democracia no Brasil encontra-se em fase de consolidação, isto é, ainda está engatinhando, o que afeta diretamente a questão da aplicação das políticas públicas e sociais, envolvendo assim aspectos da gestão pública.

Para uma experiência democrática se faz necessário o desenvolvimento de uma gestão em que o interesse público seja levado em conta na ação do governo, uma vez que alguns direitos são assegurados constitucionalmente e por vezes não garantidos pelo poder público, por uma série de motivações.

Cabral (2012) mostra que atualmente no Brasil, o terceiro setor é uma construção social que ganhou visibilidade e que congrega vários agentes. Para essa autora, o terceiro setor representa a expansão do interesse privado para o interesse público, no sentido de complementar às funções do Estado.

A ideia do Estado como único fomentador do bem público tem perdido força no caminhar da história. Assim, sociedade e mercado não se estruturam sem que haja um agente mediador, de fato democrático, nesse caso, o Estado (OLIVEIRA E PEREIRA, 2012).

A partir de Fernandez; Carraro e Menezes (2011), desde a década de 1980, os governos buscaram alternativas para manter seu nível de investimento, de maneira que não comprometessem seus orçamentos. Devido às chamadas políticas fiscais, de gastos exorbitantes no passado, algumas nações tiveram uma grande limitação na sua capacidade de ampliar o nível de gastos, principalmente, por causa do endividamento e das suas restrições de adquirir financiamento externo. 
Assim, no início dos anos 90 algumas nações europeias firmaram parceiras com o setor privado, para que esse pudesse desempenhar o papel de financiador e, no final, o agente privado poderia utilizar o resultado proveniente deste projeto, como forma de ressarcimento financeiro. (FERNADEZ; CARRARO E MENEZES, 2011)

A formatação dessa parceria gera prós e contras no que tange ao papel do Estado, sua fiscalização, seu retorno, etc. Dentre as vantagens dessa parceria está o compartilhamento de riscos entre o Estado e o setor privado. Os aspectos negativos são principalmente, que o governo perde parte da autonomia do projeto, uma vez estabelecida esse modelo de parceria, e ainda o agente público não consegue monitorar o padrão de qualidade da obra.

Assim, atualmente há a necessidade de buscar novas alternativas para essas parcerias, uma vez que tais relações tendem a ampliar as políticas públicas em variados setores, de maneira que estas coloquem em primeiro lugar o interesse público.

Há ainda outra situação que é o interesse das empresas, e/ou de particulares de aderirem a ideia de oferecer o serviço e em contrapartida receberem incentivos do governo, sobretudo devido a questões orçamentárias.

O interesse público no que tange as práticas de esporte e lazer se relaciona da seguinte maneira: são direitos constitucionalmente garantidos, que nem sempre são ofertados pelo poder público de forma satisfatória, e que a iniciativa privada, sendo empresas ou particulares, oferta, mas que deve ser fiscalizados, afinal o espaço público, é o local onde se dão as principais relações sociais, e se fazem necessários, para que de fato a experiência democrática ocorra. 


\section{Análise de Usos e Espaços}

O espaço onde acontece o lazer configura-se como um conceito relevante para nosso estudo. Buscamos na Geografia a compreensão de espaço e território, e de como se encaixam em nosso trabalho. Além disso, se faz necessário compreender como esses espaços se dividem, quem toma conta e/ou fiscaliza, isto é, os poderes que devem fazêlo.

As preocupações com o território na atualidade são recorrentes, no que tange ao que é o território, quem tem direito, que fiscaliza, quem pode ter acesso, as leis que regulamentam o uso, entre outras questões.

Uma vez que território pode ser compreendido como um espaço delimitado, a ideia de espaço, é bastante ampla. Em seu livro, "Por uma geografia nova", o autor Milton Santos, aponta que o conceito de espaço pode ser compreendido como a representação do local onde acontece as relações sociais historicamente constituídas. Ainda de acordo com Santos:

[...] O espaço por suas características e por seu funcionamento, pelo que ele oferece a alguns e recusa a outros, pela seleção de localização feita entre as atividades e entre os homens, é o resultado de uma práxis coletiva que reproduz as relações sociais, [...] o espaço evolui pelo movimento da sociedade total (SANTOS, 1978, p. 171).

Enquanto território é algo mais rígido, e se modifica a partir de tratados, o espaço se modifica a partir de seus usos e das relações sociais, costumeiras ou não. Contribuem para o uso do espaço, as atividades praticadas, a ideia de "público" que determinadas sociedades têm, a disposição desses espaços, a dinâmica urbana dos municípios a partir de seus planos diretores urbanos, etc. 
A complexidade do que é espaço, torna ainda mais densa à compreensão, desse modo, Santos, observa que “[...] o espaço organizado pelo homem é como as demais estruturas sociais, uma estrutura subordinada subordinante. É como as outras instâncias, o espaço, embora submetido à lei da totalidade, dispõe de certa autonomia." (SANTOS, 1978, p. 145)

O espaço é o local por excelência, onde se observa as principais dinâmicas da sociedade, onde as relações se dão de maneira pormenorizadas, no seu aspecto mais íntimo, uma sociedade mais desenvolvida evidenciará determinados tipos de relações, enquanto outras menos desenvolvidas e desorganizadas evidenciarão outras.

Já a compreensão de "espaço geográfico é mais amplo e complexo, entendido como um sistema indissociável de sistemas de objetos e ações, em que a instância social é uma expressão concreta e histórica" (SANTOS, 1978, p.8)

Delimitados conceitualmente, os espaços utilizados no mapeamento dessa pesquisa, passamos aos usos destes espaços, sob a ótica do lazer. Os espaços e equipamentos, frequentemente são confundidos em seus conceitos. Santini (1993) coloca que existem duas formas de entendimento para essa diferença entre conceitos. Um primeiro entendimento propõe que os conceitos sejam utilizados como sinônimos. O segundo entendimento sugere uma distinção clara entre espaço e equipamentos.

Espaço é entendido como suporte para os equipamentos. E os equipamentos são compreendidos como os objetos que organizam o espaço em função de determinada atividade.

Os equipamentos são classificados em equipamentos específicos e não específicos. Segundo Marcellino (2002), os espaços especialmente concebidos para a prática das várias atividades de lazer. São chamados de equipamentos específicos, esses 
equipamentos são os teatros, cinemas, bibliotecas etc. Onde muitas vezes a população em geral não tem acesso privilegiado a eles.

Os equipamentos não específicos para Marcellino (2002) e Bruhns e Gutierrez (2001), significam um ambiente que foi planejado e construído para uma determinada finalidade específica, não especifico para o lazer, mas que pode ser adaptado e ampliado para outras atividades, sendo então um espaço possível para aproveitar do lazer, esses equipamentos podem ser o próprio lar, bares, escolas etc.

Quando se pensa na utilização de espaços e equipamentos, em muitas situações estes não são utilizados de maneira correta, tendo o seu uso indevido, ou utilizados como mercadorias por iniciativas privadas. Ao se pensar a utilização dos espaços e equipamentos públicos de esporte e lazer, Costa (2010) afirma que a presença da iniciativa privada nesses espaços tornou-se uma ação constante que, segundo Matos (2001) denota ao espaço urbano um caráter de mercadoria, seguindo a tendência da privatização, ou seja, a comercialização do espaço urbano.

O espaço público vem seguindo a tendência de privatização e comercialização, denotando um caráter de mercadoria, restringindo seu acesso para os cidadãos que podem pagar. A privatização de espaços privados, onde muitas vezes são mantidos com financiamento público em infraestrutura e programas de animação, também se mostram de uso restrito pelo cidadão não pagante, que deveria ser beneficiado por políticas públicas, ainda que emparceiradas com a iniciativa privada.

\section{Metodologia}

Os procedimentos metodológicos para coleta de dados e construção dos conhecimentos ocorreram em três etapas. 
A primeira etapa consistiu no levantamento bibliográfico através da coleta de informações para suporte teórico, utilizando como fontes livros, artigos científicos, banco de dados e periódicos, que possibilitaram apresentar o contexto da pesquisa e os avanços nos estudos sobre esta temática. Estudo e discussão do material em levantamento. Busca e captação de documentos publicados pela gestão municipal, possibilitou identificar as políticas públicas operadas localmente, bem com as ações e projetos que estabelecem relação com a iniciativa privada e/ou ações e projetos desenvolvidos nos espaços públicos das orlas de Serra e Vitória-ES.

A segunda etapa consistiu na coleta de dados por meio de mapeamento das práticas de esporte e lazer desenvolvidos in loco nos espaços públicos investigados. A partir do material coletado, realizamos entrevistas semi-estruturadas que foram aplicadas a cada sujeito responsável por projetos de esporte e lazer que animam os espaços públicos em tela.

No protocolo para mapeamento das atividades, usamos um critério de eliminação dos questionários das atividades que ocorriam há menos de um ano, focando naquelas que tinham mais propriedade para responder as questões pertinentes as nossas discussões.

Por fim, na última etapa, buscou-se analisar de que forma a relação públicoprivado nas políticas de utilização dos espaços públicos na orla de Serra e Vitória-ES incidem sobre os direitos sociais estabelecidos constitucionalmente no acesso ao esporte e ao lazer. Para análise dos dados, optamos por aspectos relacionados aos objetivos específicos, que foram os seguintes: mapeamento das práticas corporais; (não) ocorrência da relação público-privado; (não) incidência sobre os direitos sociais constitucionalmente estabelecidos. 
Os dados foram coletados por meio de um instrumento semiaberto constituído de 22 questões. Para melhor clareza de nossa tarefa, informamos que a apresentação dos dados será pelas recorrências encontradas nas respostas às questões apresentadas, o que faremos mostrando a recorrência da resposta a cada questão específica por meio da representação RQ. (por exemplo: RQ oito, representa recorrência de respostas à questão oito).

\section{Dados Coletados e Impressões}

Não encontramos planejamentos e execuções oficiais das políticas de utilização das orlas de Serra e Vitória-ES para prática de atividades corporais, deste modo, passamos a considerar para a análise as outras fontes de informação previstas na metodologia e coletadas em campo.

Nas orlas de Serra, a utilização é bem tímida, talvez pela condição sócioeconômica do município ou por outras opções de esporte e lazer oferecidas por academias privadas.

Na Praia de Jacaraípe, município de Serra/ES, foram mapeadas seis práticas. Das seis práticas de esporte e lazer, cinco foram excluídas pela margem de corte da pesquisa. A prática que atendeu aos critérios é a modalidade surfe. O responsável pela prática é do sexo masculino, com formação completa em Educação Física. O tipo de atendimento é particular e público (singularidade a qual retornaremos adiante). No âmbito particular, são atendidas crianças, adolescentes, jovens, adultos e idosos, nos gêneros masculino e feminino. Quanto ao âmbito público, são atendidas crianças em idade escolar, também dos gêneros masculino e feminino. Quanto a ocorrência predominante dos dias e turnos de funcionamento desta prática, o atendimento particular acontece de segunda a sexta 
feira no período matutino, enquanto o atendimento público acontece nas terças e quintas feiras, nos períodos matutino e vespertino.

Já na orla de Camburi, foram detectadas várias atividades sistemáticas e contínuas como assistemáticas e esporádicas, sendo expostas a seguir:

\section{Mapeamento das Práticas}

Foram mapeadas dezoito (18) práticas corporais na orla de Vitória-ES, entre elas, o número de práticas corporais de esporte e lazer foram seis (6), as demais foram relacionadas a práticas corporais voltadas para a saúde, e dentro das seis (6) práticas de esporte e lazer mapeadas, conseguimos entrevistar cinco (5) sujeitos responsáveis pela intervenção.

Entre as cinco (5) entrevistas realizadas, duas (2) foram excluídas pela margem de corte da pesquisa, pois eram atividades que ocorriam há menos de um ano.

Entre as entrevistas realizadas as modalidades praticadas foram duas (2) de futebol de areia e uma (1) de vôlei de praia. O gênero dos responsáveis pelas atividades são uma (1) Feminino e três (3) Masculino. Há mais de um responsável em uma modalidade, a de vôlei de praia.

Os grupos sociais atendidos foram: Crianças (3), Adolescentes (2), Jovens (2), Adultos (2) e Idosos (1). Todos atendem os gêneros masculino e feminino.

\section{(Não) Ocorrência da Relação Público-Privado}

Quando perguntamos sobre o início da prática que o responsável pela atividade desenvolvia no espaço público, ou seja, para a instalação da prática, as respostas mais fortes foram "relacionadas a percepção que o espaço estava sem uso em determinados 
horários e com uso em outros por outra modalidade, sendo bom para a sua prática e havia demanda, portanto, o responsável simplesmente colocou anúncio de oferta e iniciou." Sendo que alguns responderam de maneira mais tímida, "que fizeram contato com órgãos públicos para ver se era permitido usar o espaço." (RQ 08)

Ao serem questionados a respeito de sua prática ocorrer em espaço público, portanto quais estratégias eram usadas para o contato com o setor público (governo) para o bom funcionamento da sua prática, as respostas apontaram maior incidência de "um contato informal com pessoas que são do poder público, conseguindo assim um autorização informal (de boca) das mesmas para funcionar." Porém alguns disseram constituir grupo de sujeitos que trabalham no espaço, "participando de reuniões e encontros que se propõem regular o uso dos espaços." (RQ 14)

Já quando perguntamos quanto a existência de mecanismos de controle e fiscalização por parte do poder público, a maioria afirmou que "não acontece, que cada um trabalha no espaço e se mantém pela qualidade do seu trabalho." (RQ 15)

Apesar de afirmarem não ocorrer fiscalização, quando perguntamos se em alguma rara vez ocorreu qualquer tipo de fiscalização no uso do espaço, ou questionamento quanto à cobrança para este uso, informaram que "há relatos de visita de órgãos municipais e conselhos profissionais." (RQ 16)

E quando questionamos sobre questões gerais que envolvem o uso do espaço onde suas práticas acontecem e o uso por outros sujeitos, nos informaram que "a antiguidade é posto, quem está trabalhando há mais tempo tem direito ao espaço, quem chega depois que procure outro." Sendo que alguns disseram que "o espaço é público e não tem regulamentação específica, portanto, em cada dia de trabalho, quem ocupa primeiro tem a prioridade." (RQ 18) 
Neste aspecto da falta de regulamentação, também há evidências de que isto ocorra na praia de Serra/ES, pois ficou evidenciado pelo sujeito que há uma informalidade nas relações estabelecidas com o Poder Público quanto à permissão para o uso do espaço.

\section{(Não) Incidência sobre os Direitos Sociais Constitucionalmente Estabelecidos}

Ao perguntarmos sobre as dificuldades ou facilidades de se instalar neste espaço, "os responsáveis disseram que houve facilidade porque no espaço não existem atividades ofertadas pelo Poder Público, e há pessoas interessadas nas práticas, uma vez que há carência dessas práticas também em outros espaços públicos ou privados." (RQ 09)

Já ao serem questionados sobre as estratégias que os responsáveis usam para manter o funcionamento da prática, nos responderam que "o funcionamento das atividades é mantido pelo pagamento dos praticantes, sem qualquer participação da prefeitura ou de outro órgão público, e que havia patrocínios e parcerias com outras instituições (clubes, colégios, associações, etc.)." Alguns disseram que "há promoções para captar interessados, tais como 'pacotes' entre duas ou mais pessoas da mesma família, descontos para pessoas com menor renda, etc." (RQ 10)

Sobre o perfil sócio-econômico dos indivíduos que aderiram a proposta de atividade dos responsáveis, nos informaram que "a maioria era de classe alta e média alta, sem informação real da renda, mas quanto ao local de residência e posse de bens, indicavam alto poder aquisitivo." Em menos casos houve também a resposta que "não era identificada a classe social, pois não há controle sobre isso, porém, aparentemente todos têm condições de pagar os valores cobrados." (RQ 12) 
Ainda falando sobre o perfil sócio-econômico dos clientes, questionamos se existem estratégias para agregar pessoas com outros perfis, a fim de aumentar o número de praticantes, e responderam que "permitiam fazer uma aula experimental para provocar o gosto pelo 'quero mais', sendo que com menos intensidade surgiu a resposta do feitio de promoções do tipo: quem trouxer mais uma pessoa, ganha desconto." (RQ 13)

E sobre questões gerais que envolvem o uso do espaço onde as práticas acontecem, os responsáveis informaram que "seria muito bom fazer parcerias formais com o poder público, em que houvesse regulação do uso dos espaços e possibilidade de convênios com financiamento público para as atividades desenvolvidas, ampliando assim o número de praticantes que não podem pagar, mesmo permanecendo como iniciativa privada." (RQ 17)

\section{Discussões e Conclusões}

Temos um trabalho com foco político e de acordo com Bobbio (2000), "O conceito de política, entendida como forma de atividade ou práxis humana, está estreitamente ligada ao conceito de poder" (p. 160), ou seja, as 'coisas' são como são pelas escolhas de determinados agentes de poder decisório de natureza política.

Essas ‘coisas' analisadas são definidas pelas políticas públicas, como exemplo: o investimento em ações de esporte, em espaços de lazer, etc., dependem de vontade política para acontecer, deixar de acontecer, evoluir ou regredir. Deste modo Azevedo (2001), afirma que:

[...] as políticas públicas são definidas, implementadas, reformuladas ou desativadas com base na memória da sociedade ou do Estado em que têm lugar e por isso guardam estreita relação com a as 
representações sociais que cada sociedade desenvolve sobre si própria. (p.6)

Deste modo, para determinada política pública vir a ser, a memória e vontade coletiva precisam pressionar determinados agentes políticos selecionados, para que estes representantes venham a fazer valer essas representações sociais, que a sociedade acredita ter de si. Como Sousa e Antunes (2008) analisaram:

[...] a partir de questões socialmente problematizadas, surgem políticas públicas para determinado setor, há um "reconhecimento" por parte do Estado desta necessidade/problema, e a política pública específica do setor virá para "suprir" os anseios de determinada representação social (p.6).

Por esta razão, seria interessante a educação política dos cidadãos, para que a sociedade possa apresentar propostas de políticas públicas para as problematizações sociais surgidas, e a partir desta pressão social o Estado 'reconhecer' e criar políticas públicas para atender estes anseios.

Uma causa da dificuldade na educação política pode vir da própria palavra 'política', que além das conotações negativas que vem carregando atualmente, tem aspectos semânticos na própria palavra que não trazem uma clareza evidente. Heidermann e Salm (2009) identificaram essas dificuldades e problematizaram da seguinte maneira:

A expressão "política pública" (no inglês, public policy causa espécie em língua portuguesa. Por que seria necessário reassegurar o caráter público a uma palavra derivada de polis, o Estado helênico clássico? A própria palavra "política", por si só, já suscita um mundo de discordâncias no diálogo e nos debates entre as pessoas. Por isso, cabe fazer aqui um pequeno esclarecimento para tentar compreender e superar a polissemia; isto é, torna-se necessário discernir as principais significações atribuídas ao termo "política". Só então se pode firmar a noção de política pública (p.28-29). 
Notamos redundância na expressão 'política pública', visto que a palavra política por si só já é referente às relações sociais, e a polissemia atribuída a palavra pode ser a causa dessa confusão. Frey (2000) clareia essa discussão ao definir três dimensões a essa palavra:

[...] a literatura sobre 'policy analysis' diferencia três dimensões da política. Para a ilustração dessas dimensões tem-se adotado na ciência política o emprego dos conceitos em inglês de 'polity' para denominar as instituições políticas, 'politics' para os processos políticos e, por fim, 'policy' para os conteúdos da política:

- a dimensão institucional 'polity' se refere à ordem do sistema político, delineada pelo sistema jurídico, e à estrutura institucional do sistema político-administrativo;

- no quadro da dimensão processual 'politics' tem-se em vista o processo político, freqüentemente de caráter conflituoso, no que diz respeito à imposição de objetivos, aos conteúdos e às decisões de distribuição;

- a dimensão material 'policy' refere-se aos conteúdos concretos, isto é, à configuração dos programas políticos, aos problemas técnicos e ao conteúdo material das decisões políticas (p. 216-217).

Então política é tanto o sistema político (instituições, regras...), como o processo de conflito de ideias (jogo de persuasão e interesses), quanto àquilo que se concretiza e chega efetivamente à população. Nestes três significados (sistema, conflitos e produto), vemos que não há como escapar das 'políticas' ao discutir qualquer problemática social. Acreditamos que para entendermos melhor e para atribuir uma análise melhor a nosso trabalho, nosso foco deve ser nesta distinção tripla, também apontada por Souza (2006):

O primeiro, seguindo a tradição de Madison, cético da natureza humana, focalizava o estudo das instituições, consideradas fundamentais para limitar a tirania e as paixões inerentes à natureza humana. O segundo caminho seguiu a tradição de Paine e Tocqueville, que viam, nas organizações locais, a virtude cívica para promover o "bom" governo. O terceiro caminho foi o das políticas públicas como um ramo da ciência política para entender como e por que os governos optam por determinadas ações (p.22). 
Entender como e por que certas opções são tomadas, tanto para investimento em esporte e lazer, como corte de orçamento, ampliação de políticas públicas existentes ou redução/finalização de projetos em andamento, pode ser um bom balizador, e por si só dá um bom norte para o embasamento de um estudo explicativo.

Certos fenômenos que notamos na política de modo geral é a forma como os gestores encaram as necessidades de ação: ou por necessidade de poder político puro ou pela necessidade da resolução de algum problema por pressão social. Souza (2006) explica que:

Quando o ponto de partida da política pública é dado pela política, o consenso é construído mais por barganha do que por persuasão, ao passo que, quando o ponto de partida da política pública encontra-se no problema a ser enfrentado, dá-se o processo contrário, ou seja, a persuasão é a forma para a construção do consenso (p.30).

Enquanto a barganha geralmente é baseada na resolução de interesses próprios e troca de favores, a persuasão pode ser tanto por poder atual, como o de convencimento explicativo que determinado investimento e ampliação de orçamento em determinado setor faz-se necessário. Acreditamos que este último caminho pode ser obtido tanto pela pressão social, como por estudos que clareiem e analisem determinados fenômenos, a fim de dar subsídios e argumentos para o processo decisório dos governantes. Esta necessidade de fazer com que o governo 'aja' é definido assim por Souza (2006):

Pode-se, então, resumir política pública como o campo do conhecimento que busca, ao mesmo tempo, "colocar o governo em ação" e/ou analisar essa ação (variável independente) e, quando necessário, propor mudanças no rumo ou curso dessas ações (variável dependente) (p.26). 
Acreditamos que o presente estudo poderá contribuir neste sentido, analisando, descrevendo e tentando explicar determinadas realidades sociais que encontramos em campo.

Estas realidades sociais, que são diretamente e indiretamente causadas pelas decisões políticas (investimento, corte, ampliação ou redução em determinadas áreas), se dão como o contraste urbano que pretendemos esmiuçar futuramente, como apontou Pellegrin (2004), em seu livro crítico de equipamentos de lazer: [...] ao mapear uma cidade e os equipamentos de lazer que nela existem, contrastes urbanos diversos se fazem claros aos nossos olhos (PELLEGRIN, 2004, p. 72).

Mais especificamente na nossa pesquisa, notamos que a exploração privada dos espaços públicos para práticas de esporte e lazer vem ocorrendo em diversas localidades, principalmente nas partes privilegiadas das cidades, como as orlas urbanizadas. Faz-se necessária a discussão desses usos, passando por diversos assuntos sociológicos e antropológicos para uma análise de maior qualidade, utilizando temas dessas áreas como desigualdade, classes, políticas públicas, educação, profissionalismo, além de discussões nos campos da saúde, sobretudo a educação física.

Nas análises de políticas públicas relacionadas a lazer encontramos um indicador importante que é a concepção que os gestores têm de lazer (MARCELINNO, 2001), e através desta análise justifica-se o crescimento de políticas de governo nesse setor nos últimos anos sustentadas no direito social garantido constitucionalmente (BORGES et al., 2009; AREIAS; BORGES, 2011).

A partir deste ponto discutiremos os dados levantados e relacioná-los com as leituras feitas ao longo da pesquisa, lembrando que nossos objetivos específicos são identificar as políticas públicas de utilização do espaço público de esporte e lazer, não 
tendo encontrado documentos específicos sobre a temática, analisar como ocorre e se ocorre parceria entre iniciativa privada e poder público, onde notamos extrema fragilidade nesta relação e por fim, compreender se e como as políticas de utilização incidem sobre os direitos sociais, tendo notado a inexistência, consideramos que as mesmas não incidem sobre os direitos constitucionalmente estabelecidos.

Pelo mapeamento, pode-se observar uma quantidade considerável de intervenções por iniciativa privada na orla de Vitória, ocupando espaço e tempo, da mesma forma, parecer haver uma demanda considerável de pessoas que buscam práticas orientadas de saúde e, para o interesse desse trabalho, de esporte e lazer.

Sabe-se que a orla de Vitória possui 04 módulos do Serviço de Orientação ao Exercício (SOE), sendo 02 na Praia de Camburi, 01 na Praça dos Desejos e 01 na Prainha de Santo Antônio (BACHETTI, 2014). Enquanto Política Pública, este quantitativo frente ao número de intervenções que mapeamos é claramente insatisfatório, o que nos permite inferir insuficiência de atendimento em práticas regulares de esporte e lazer de forma pública e gratuita a um número considerável de cidadãos da cidade. Mas, como o atendimento é realizado por iniciativas privadas, sugere-nos a indagação: Qual a relação entre o poder público e os intervenientes privados?

As evidências apontam que a relação público-privado é bastante frágil, considerando aspectos relacionados a regulamentação do espaço, a tributação, a fiscalização, incentivos e uso da força. Uso da força, este definido como força policial ou poder de polícia, na garantia das deliberações do governo e 'ordem' pública. 
Além de apontarem também que a forma como as intervenções são feitas tem pouca possibilidade de se efetivarem como políticas públicas (em parceria com o estado), a favor dos direitos sociais constitucionalmente estabelecidos.

Notamos que o esporte e lazer, tornaram-se assuntos relevantes nas discussões acadêmicas e gestão pública, essencialmente após a Constituição Federal de 88, ao considerá-los direitos de todos os cidadãos. E vemos historicamente, as políticas públicas de esporte e lazer no Brasil, apresentarem as características de seletividade, fragmentação, exclusão, setorialização e assistencialismo (BONALUME, 2011). Percebemos que a orla privilegiada fragmenta a população, seleciona os possuidores de mais recursos e exclui aqueles que não tem condições financeiras, deixando um ente privado atuar sem regulamentação, e os praticantes serem apenas os que podem pagar, mesmo em zona pública.

Há o crescimento de políticas de governo neste setor, especialmente nos últimos anos sustentadas no direito social garantido constitucionalmente (BORGES et al., 2009; AREIAS; BORGES, 2011), e no caso específico de Vitória-ES, vemos o SOE (Serviço de Orientação ao Exercício), como proposta que apareceu nos nossos mapeamentos e tem como característica exclusiva a oferta pública de práticas corporais com foco na promoção da saúde. Porém Carvalho (2008) atenta para a necessidade de participação política para a busca de garantia dos direitos sociais, trazendo a população para auxílio na formulação e execução das políticas públicas.

Walter (2004) destacou três fatores importantes para a compreensão da formação da estrutura de esporte e lazer municipais, sendo: a criação de espaços públicos; a influência do planejamento urbano da cidade nas práticas esportivas desenvolvidas; e a proposta de descentralização das ações de esporte e lazer. Onde o poder público não 
atua, a iniciativa privada vem e ocupa, e esta presença privada nos espaços públicos pode trazer, segundo Matos (2001), um caráter de mercadoria ao espaço urbano, trazendo elementos de privatização, comercialização do espaço urbano. Sendo assim, o poder público precisa de uma visão ampla e integrada para utilizar o espaço urbano em prol da população, garantindo o acesso às práticas de esporte e lazer para todos os cidadãos nestes espaços públicos (MARCELLINO, 2007). Assim sendo, notamos a ausência do estado nestes espaços públicos, gerando uma situação de clientelismo que é segundo Farias (2000, p.49) a 'apropriação privada da coisa pública'.

Nas nossas visitas, encontramos diversas práticas no uso da orla de Vitória, tanto sistemáticas e contínuas, como assistemáticas e esporádicas, que revelaram uma ausência de fiscalização e controle por parte do poder público no uso desses espaços.

Percebemos que a ocorrência da relação público-privado é frágil, visto que os responsáveis simplesmente chegaram aos espaços e começaram suas atividades, sendo estas com mais de um ano de duração. Alguns poucos tentaram contato com órgãos públicos, mas a autorização que disseram ter ocorrido foi informal, 'de boca', ficando a cargo dos próprios utilizadores da região, encontros para tratar desta regulação de uso. Além de informarem não haver fiscalização, ouviram dizer que órgãos municipais e conselhos de classe já realizaram visita. Deste modo, eles próprios criaram regras informais de uso, sendo a prioridade dada aos mais antigos a utilizarem à orla.

Já em relação aos direitos sociais ao esporte e lazer, constitucionalmente estabelecidos, também notamos não haver esta incidência, pois informaram não haver atividades ofertadas pelo Poder Público, mas haverem pessoas interessadas nestas atividades. Desta forma, não havia auxílio por parte do governo para o desenvolvimento das modalidades, sendo o perfil mais identificado o de classe alta e média alta, 
permanecendo nas atividades, em quase hegemonia, aqueles que têm condições financeiras de pagar. Pessoas de outros perfis têm direito apenas a uma 'aula experimental' e caso capte outros participantes, pode haver um desconto. Porém notamos que os responsáveis se mostraram abertos à formalização das atividades com o Poder Público, constituindo regulação, convênios e ampliação dos praticantes mesmo entre os que não têm condições de pagar.

Diante do exposto, nossa percepção geral é que os resultados apontam para concepções sobre espaço público como espaço para todos, mas, ocupado de acordo com interesses pessoais; concepção unívoca de benefícios nas parceiras e; oferta de serviços sem institucionalização e regulamentação, mostrando ausência de responsabilidades do Estado.

Acreditamos que as reflexões encontradas podem servir como aporte para o planejamento de políticas públicas e legislação, de participação, intersetorialidade e na relação público-privada no campo de esporte e lazer, além de futura relação com outros subprojetos ou pesquisas similares realizadas em outras regiões do Espírito Santo, e até mesmo em outros estados brasileiros.

\section{REFERÊNCIAS}

AREIAS, K. T. V; BORGES, C. N. F. As Políticas Públicas de Lazer na Mediação entre Estado e Sociedade: Possibilidades e Limitações. Revista Brasileira de Ciências do Esporte. Campinas - São Paulo: Autores Associados, 2011.

AZEVEDO, J. M. L. A educação como política pública. Campinas: Autores associados, 2001.

BACHETTI, J.R. Limites e Possibilidades da Educação Física nas Políticas Públicas de Saúde de Vitória - ES. Dissertação (Mestrado em Educação Física) - Programa de Pós-Graduação em Educação Física da Universidade Federal do Espírito Santo: Vitória, 2014.

BARDIN, Laurence. Análise de conteúdo. 4. ed. Lisboa: Edições 70, 2009. 
BOBBIO, N. Teoria geral da política: a filosofia política e as lições dos clássicos. Rio de Janeiro: Campus, 2000.

BONALUME, C. R. O paradigma da intersetorialidade nas políticas públicas de esporte e lazer. Licere, v. 14, n.1, Belo Horizonte, 2011.

BORGES, C. N. F. et al. Políticas Públicas de Esporte e Lazer no Espírito Santo: Políticas de Governo X Políticas de Estado. In: CONGRESSO BRASILEIRO DE SOCIOLOGIA: Consensos e controvérsias. 14. Anais ...Rio de Janeiro: SBS/UFRJ, 2009.

BRASIL. Constituição da República Federativa do Brasil. Brasília: Senado Federal: Centro Gráfico, 1988. 292 p.

BRUHNS, Heloisa T.; GUTIERREZ, Gustavo Luiz. Representações do lúdico: II ciclo de debates lazer e motricidade. Campinas: Autores Associados, 2001.

CABRAL, F.H.S. Desenvolvimento e terceiro setor: possibilidades globais e escolhas locais. Revista Ciriec Brasil. Salvador. V.1 n.1.2012.

CARVAlHO, J. M. Cidadania no Brasil: o longo caminho. 10. ed. Rio de Janeiro: Civilização Brasileira, 2008.

COSTA, J. H. Parceria público privada na gestão municipal do lazer: encontros e desencontros na "Praça da Criança" na cidade de Mossoró/ RN. Revista Espaço Acadêmico, ano X, n.12, 2010. p. 88-98.

FARIAS, Francisco Pereira de. Clientelismo e democracia capitalista: elementos para uma abordagem alternativa. Sociologia e Política, Curitiba, v.1, n. 15, nov. 2000, pp. 49- 65.

FERNANDEZ, Rodrigo Nobre; CARRARO, André; MENEZES, Gabrielito. Parcerias público-privadas: Um modelo teórico aplicado a hospitais. In: ENCONTRO NACIONAL DE ECONOMIA. 34. Foz do Iguaçu/PR. Anais... Associação Nacional de Pesquisadores em Economia (ANPEC): 2011. Disponível em: $<$ https://www.anpec.org.br/encontro/2011/inscricao/arquivos/0006c6ec0d6af5c4ed1 01 bcd1cd169cf7d2.pdf $>$ Acesso em: 12 set. 2015.

FREY, K. Políticas Públicas: um debate conceitual e reflexões referentes à prática da análise de políticas públicas no Brasil, Planejamento e Políticas Públicas, n. 21, Jun. 2000, p.211-259.

HEIDEMANN, F. e SALM, J. F.. Políticas públicas e Desenvolvimento: bases epistemológicas e modelos de análise. Brasília: Editora UnB.2009.

MARCELlinO, N. C. Lazer e esporte: políticas públicas. Campinas: Autores Associados, 2001.

. Estudos do lazer: uma introdução. Campinas, 2002. 
. et al. Espaços e equipamentos de lazer em região metropolitana: o caso da $\overline{\mathrm{RMC}}$ - Região Metropolitana de Campinas. Curitiba: OPUS, 2007.

MATOS, L. S. Belém: do direito ao lazer ao direito à cidade. In: MARCELLINI, N. C. Lazer e esporte: políticas públicas. Campinas: Autores Associados, 2001.

OLIVEIRA, V.A.R. de. PEREIRA, J.R. O público estatal e não estatal na delimitação do campo da gestão pública. In: ENCONTRO DE ADMINISTRAÇÃO, POLÍTICAS E GOVERNO. Anais... Salvador/BA. Associação Nacional de Pós-Graduação e Pesquisa em Administração (ANPAD): 2012. Disponível em: < https://www.anpad.org.br/diversos/trabalhos/EnAPG/enapg_2012/2012_EnAPG176.pdf $>$ Acesso em: 12 maio 2016.

PELLEGRIN, A. Equipamento de lazer. In: GOMES, C. L. Dicionário crítico do lazer. Belo Horizonte: Autêntica, 2004. p.69-72.

SANTINI, R. de C. G. Dimensões do lazer e da recreação. São Paulo: Angelotti, 1993.

SANTOS, M. Por uma Geografia Nova. São Paulo: Hucitec, Edusp, 1978.

SOUSA, R.L.Q. e ANTUNES, M.F.S. Os Espaços Públicos de Lazer para a Prática Esportiva: Mapeando a Cidade de Uberlândia - MG. Pesquisa de Pibic/CNPq (20072008) para Faculdade de Educação Física - Universidade Federal de Uberlândia. Uberlândia - MG. 2008.

SOUZA, Celina. Políticas públicas: uma revisão da literatura. Sociologia, Porto Alegre, ano 8, n. 16, jul/dez 2006, p. 20-45.

WALTER, M. R. Políticas públicas e descentralização do esporte e lazer da prefeitura municipal de Curitiba: gestão 1997-2000 e 2001-2004. 2004. $101 \mathrm{f}$. Dissertação (Mestrado em Educação Física) - Programa de Pós-Graduação e, Educação Física da Universidade Federal do Paraná: Curitiba, 2004.

\section{Endereço dos Autores:}

Leonardo Perovano Camargo

Rua Santa Catarina, 223, Carapina

Serra - ES - 29.160-104

Endereço Eletrônico: leonardoperovano@gmail.com

Lorenna Pereira Oliosi

Avenida Gonçalves Ledo, 672, Cristóvão Colombo

Vila Velha - ES - 29.106-340

Endereço Eletrônico: lorenna.oliosi@hotmail.com

Junia Helena dos Santos

Avenida Manoel Jacinto da Silva, 1028, Vista da Serra 1 
Serra - ES - 29.176-358.

Endereço Eletrônico: juniahelena@hotmail.com

Carlos Nazareno Ferreira Borges

Rua Niterói, 204, Conjunto Marex, Bairro Val de Cans

Belém - PA - 66.617-110

Endereço Eletrônico: naza_para@yahoo.com.br

Kamila da Penha Braz DeFante

Rua Nove, 246, Maracanã

Cariacica - ES - 29.142-873

Endereço Eletrônico: kamila.braz92@hotmail.com 